\title{
Interventional post-myocardial infarction ventricular septal defect closure: a systematic review of current evidence
}

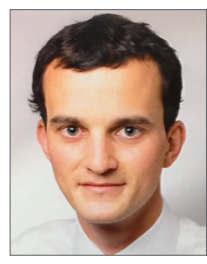

Florian Schlotter ${ }^{1}, \mathrm{MD}$; Suzanne de Waha², MD; Ingo Eitel², MD; Steffen Desch², MD; Georg Fuernau², MD; Holger Thiele²*, MD

1. University of Leipzig - Heart Center, Leipzig, Germany; 2. University Heart Center Lübeck, University Hospital Schleswig-Holstein, Lübeck, Germany

F. Schlotter and S. de Waha contributed equally to this manuscript.

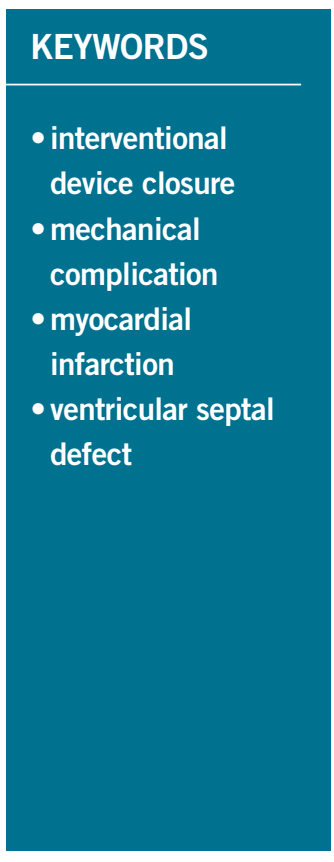

\begin{abstract}
Aims: Interventional closure of post-myocardial infarction ventricular septal defects (VSD) is an alternative treatment option to surgical repair. However, only limited evidence exists concerning the interventional closure of a VSD. This review seeks to establish an overview of the existing literature and to carry out a systematic analysis of the success rate and clinical outcome of this procedure.
\end{abstract}

Methods and results: We conducted a comprehensive systematic literature search to evaluate the existing evidence of percutaneous device closure of post-infarction VSD. Patient series with fewer than five reported cases were excluded. In total, 13 series were identified, with an overall inclusion of 273 patients. Mean patient age was 70 years. Cardiogenic shock was present in $48 \%$ of cases at the time of intervention. Device closure within the first 14 days (acute phase) after VSD detection was performed in $42 \%$ of cases. Technical success rate was high (>75\%). Successful device implantation rate was $89 \%$. Overall inhospital/30-day mortality was 32\%. Major complications included device embolisation, ventricular perforation and arrhythmias.

Conclusions: Percutaneous device closure of post-myocardial infarction VSD is a valuable alternative to surgical repair, with the advantage of immediate shunt reduction to prevent haemodynamic deterioration. A high rate of technically successful percutaneous procedures can be achieved; however, the mortality rate remains high, especially in cardiogenic shock patients.

\footnotetext{
*Corresponding author: Medical Clinic II - Cardiology/Angiology/Intensive Care Medicine, University Heart Center Lübeck,
} University Hospital Schleswig-Holstein, Ratzeburger Allee 160, 23538 Lübeck, Germany.E-mail: Holger.Thiele@uksh.de 


\section{Introduction}

Post-infarction ventricular septal defect (VSD) is an infrequent but life-threatening complication following acute myocardial infarction (AMI). Data from thrombolytic management of AMI suggest an incidence of ventricular septal rupture of $0.2 \%$, with a median time from myocardial infarction to VSD development of one day ${ }^{1}$. Only limited data exist on the frequency of post-infarct VSD in the interventional era. VSD complicating AMI frequently leads to cardiogenic shock $(\mathrm{CS})^{2}$.

To date, three treatment options exist: 1) medical management, 2) surgical repair, and 3) interventional closure. Medical management carries a grim prognosis with a $94 \%$ mortality rate at 30 days $^{1}$. Although open heart surgery is considered standard treatment for VSD, catheter-based intervention has emerged as a promising alternative $e^{3-5}$. The exact timing for closure remains a matter of debate. Current guidelines recommend urgent VSD closure, irrespective of haemodynamic status ${ }^{3-5}$, but surgeons often refrain from very early surgery due to extremely poor results. Instead, surgical repair is often only performed several weeks after myocardial infarction, which inevitably leads to selection of a healthier population eventually undergoing surgery (due to deaths while waiting for surgery).

In 1988, Lock and colleagues first reported on an interventional approach for post-infarct VSD closure $^{6}$. Since this first report, transcatheter VSD closure has become a viable treatment option. Previously published case series of catheter-based VSD closure were usually restricted to an interventional approach during the subacute and chronic periods after VSD occurrence, with only one larger series demonstrating feasibility in the acute setting ${ }^{7}$. The general management of post-infarction VSD has recently been reviewed; however, it was not focused primarily on interventional management ${ }^{8}$.

Therefore, the aim of the present review was to provide a comprehensive overview of the current evidence including success rate and complications of interventional VSD closure in patients with post-infarction VSD.

\section{Methods \\ DATA ACQUISITION}

We conducted a comprehensive literature search of MEDLINE, EMBASE, CENTRAL and ClinicalTrials.gov, using the following subject headings: "ventricular septal defect", "ventricular septal rupture", "myocardial infarction", "closure", "septal occluder device", "transcatheter", "percutaneous", in order to identify randomised trials, registries and case series.

No restrictions on publication date or language were applied. Duplicate papers were manually removed from the search results. Additionally, a manual search by examining reference lists from research papers and review articles was performed.

Three authors (FS, IE, SW) independently screened all titles and abstracts and excluded papers on the basis of predefined criteria. Disagreements were resolved by consensus. Case reports and case series including only a limited number of patients $(<5)$ were excluded. Furthermore, case series reporting closure of non-infarction VSDs were omitted.

We included publications on secondary VSD closures after primary surgical closure attempts with residual shunt if those were outlined in the same report as primary transcatheter closure cases. No further restrictions were applied.

Articles were rejected on initial screening if titles or abstracts were clearly irrelevant. The full text of potentially relevant articles was reviewed to assess eligibility for inclusion in the analysis.

This study was conducted in compliance with the Preferred Reporting Items for Systematic Reviews and Meta-Analyses (PRISMA) statement ${ }^{9}$. A standardised form was used to extract study data, including a description of the study population, patient characteristics, procedure characteristics, complications, as well as the nature and number of clinical events.

\section{STATISTICAL ANALYSIS}

As the search found no randomised controlled trials, we sought to establish a statistical approach to a systematic review of the individual studies within the limitations of a non-randomised data environment. The following clinical endpoints were included in the analysis: in-hospital/30-day mortality, complications, baseline characteristics (age, gender, number of diseased coronary vessels, infarct location, VSD location, time from AMI to VSD, time from VSD to closure, presence of CS, prior intra-aortic balloon pump [IABP] use, secondary percutaneous closure attempt), and procedural characteristics (successful device implantation, type of occluder). For determination of the mortality rate (in-hospital/30day mortality if specified), we calculated the absolute number of events and their sum as a percentage of the total population investigated. Procedure-related complications are outlined in detail under the precondition that they were reported and considered procedure-related by the individual study authors. Continuous data are presented as means and standard deviations. A two-sided p-value $<0.05$ was considered statistically significant.

\section{Results}

The literature search identified 13 publications reporting on interventional VSD closure, representing the composite experience of 38 centres (Table 1). All series were published between 2004 and 2015. Underlying data were collected from 1988-2012. The total number of patients was 273. Most studies were retrospective ${ }^{10-19}$, with three prospective analyses ${ }^{7,20,21}$. No randomised trials were identified.

A secondary percutaneous approach after primary surgical VSD closure was performed in $16.5 \%$ of patients (45/273). In this patient population, 33 patients were treated for residual or recurrent $\mathrm{VSD}^{10,12,13,17}$, two patients for a surgical patch dehiscence $^{11}$, and 10 patients without further notion of the reason for the secondary percutaneous approach ${ }^{20}$. The number of patients, year of publication, number of acute phase and chronic phase patients after VSD detection, 30-day or in-hospital mortality, number of CS patients, number of successful device 
Table 1. Characteristics of studies: baseline variables.

\begin{tabular}{|c|c|c|c|c|c|c|}
\hline Study & Patients & Year & Age; years & $\begin{array}{c}\text { Closure <2 weeks; } \\
\text { n/N (\%) (days) }\end{array}$ & $\begin{array}{c}\text { Closure } \geq 2 \text { weeks; } \\
\text { n/N (\%) (days) }\end{array}$ & Device type \\
\hline $\begin{array}{l}\text { Assenza et } \\
\mathrm{al}^{10}\end{array}$ & 30 & 2013 & $\begin{array}{c}67 \pm 8 \\
(-)\end{array}$ & - & $\begin{array}{l}- \\
(-)\end{array}$ & $\begin{array}{l}\text { 1988-97 Clamshell device, 1994-2008 } \\
\text { CardioSEAL, after } 2001 \text { STARFlex }\end{array}$ \\
\hline $\begin{array}{l}\text { Ahmed et } \\
\mathrm{al}^{11}\end{array}$ & 5 & 2008 & $\begin{array}{l}\text { 72, IQR 66-76 } \\
\text { (range 66-76) }\end{array}$ & $\begin{array}{l}2 / 5(40) \\
(6 \pm 6)\end{array}$ & $\begin{array}{l}3 / 5(60) \\
(48 \pm 6)\end{array}$ & $\begin{array}{l}\text { AMPLATZER post-infarction Muscular VSD } \\
\text { Occluder }\end{array}$ \\
\hline $\begin{array}{l}\text { Bialkowski } \\
\text { et } \mathrm{al}^{12}\end{array}$ & 19 & 2007 & $\begin{array}{c}66 \pm 9 \\
\text { (range } 51-81 \text { ) }\end{array}$ & $\begin{array}{c}1 / 19(5) \\
(-)\end{array}$ & $\begin{array}{c}18 / 19(95) \\
\text { (range } 24-84 \text { ) }\end{array}$ & $\begin{array}{l}17 \text { AMPLATZER Septal Occluder, } 2 \text { AMPLATZER } \\
\text { Muscular VSD Occluder, } 2 \text { AMPLATZER } \\
\text { post-infarction Muscular VSD Occluder }\end{array}$ \\
\hline $\begin{array}{l}\text { Calvert et } \\
\text { al }^{13}\end{array}$ & 53 & 2014 & $\begin{array}{c}72 \pm 11 \\
(-)\end{array}$ & $\begin{array}{c}29 / 53(55) \\
(-)\end{array}$ & $\begin{array}{c}24 / 53(45) \\
(-)\end{array}$ & $\begin{array}{l}17 \text { AMPLATZER Muscular VSD Occluder, } 34 \\
\text { AMPLATZER post-infarction Muscular VSD } \\
\text { Occluder, } 2 \text { other }\end{array}$ \\
\hline $\begin{array}{l}\text { Demkow } \\
\text { et } \mathrm{al}^{14}\end{array}$ & 11 & 2005 & $\begin{array}{c}68( \pm-) \\
\text { (range 52-81) }\end{array}$ & $\begin{array}{l}1 / 11(9) \\
\text { (day 2) }\end{array}$ & $\begin{array}{l}10 / 11(91) \\
(131 \pm 154)\end{array}$ & AMPLATZER Septal Occluder \\
\hline $\begin{array}{l}\text { Holzer et } \\
\text { al }^{20}\end{array}$ & 18 & 2004 & $\begin{array}{l}75, \text { IQR 52-86 } \\
\text { (range 52-86) }\end{array}$ & $\begin{array}{c}5 / 18 \text { (28) } \\
\text { (within } 6 \text { days) }\end{array}$ & $\begin{array}{c}13 / 18(72) \\
\text { (range 14-95) }\end{array}$ & $\begin{array}{l}\text { AMPLATZER post-infarction Muscular VSD } \\
\text { Occluder }\end{array}$ \\
\hline $\begin{array}{l}\text { Maltais et } \\
\mathrm{al}^{15}\end{array}$ & 12 & 2009 & $\begin{array}{l}68 \pm 9 \\
\text { (range 52-85) }\end{array}$ & $\begin{array}{l}12 / 12(100) \\
(4.0 \pm 4.4)\end{array}$ & 0 & $\begin{array}{l}\text { AMPLATZER post-infarction Muscular VSD } \\
\text { Occluder }\end{array}$ \\
\hline $\begin{array}{l}\text { Marinakis } \\
\text { et al }{ }^{16}\end{array}$ & 8 & 2007 & $\begin{array}{c}76 \pm 6 \\
\text { (range } 67-83 \text { ) }\end{array}$ & $\begin{array}{c}6 / 8(75) \\
(-)\end{array}$ & $\begin{array}{c}2 / 8(25) \\
(-)\end{array}$ & AMPLATZER Muscular VSD Occluder \\
\hline $\begin{array}{l}\text { Martinez } \\
\text { et al }{ }^{17}\end{array}$ & 5 & 2007 & $\begin{array}{c}66 \pm 16 \\
\text { (range 51-88) }\end{array}$ & $\begin{array}{c}3 / 5(60) \\
(-)\end{array}$ & $\begin{array}{c}2 / 5(40) \\
(-)\end{array}$ & $\begin{array}{l}2 \text { AMPLATZER Septal Occluder, } 3 \text { AMPLATZER } \\
\text { post-infarction Muscular VSD Occluder, } 1 \\
\text { AMPLATZER Muscular VSD Occluder }\end{array}$ \\
\hline $\begin{array}{l}\text { Thiele et } \\
\mathrm{al}^{7}\end{array}$ & 29 & 2009 & $\begin{array}{c}71 \pm 8 \\
\text { (range 58-84) }\end{array}$ & $\begin{array}{l}29 / 29(100) \\
(1[\text { IQR } 1-3])\end{array}$ & 0 & $\begin{array}{l}\text { AMPLATZER Septal Occluder/AMPLATZER } \\
\text { Muscular VSD Occluder }\end{array}$ \\
\hline $\begin{array}{l}\text { Trivedi et } \\
\text { al }^{18}\end{array}$ & 6 & 2015 & $\begin{array}{c}75, \text { IQR } 76-85 \\
(-)\end{array}$ & $\begin{array}{l}- \\
(-)\end{array}$ & $\begin{array}{l}- \\
(-)\end{array}$ & $\begin{array}{l}\text { AMPLATZER Septal Occluder, AMPLATZER } \\
\text { post-infarction Muscular VSD Occluder, } \\
\text { AMPLATZER Muscular VSD Occluder, } \\
\text { AMPLATZER "Cribriform" Occluder }\end{array}$ \\
\hline Xu et al ${ }^{19}$ & 42 & 2014 & $\begin{array}{c}65 \pm 4 \\
(-)\end{array}$ & $\begin{array}{c}9 / 42(21) \\
(7[\text { IQR } 5-12])\end{array}$ & $\begin{array}{c}33 / 42(79) \\
(30[I Q R \text { 18-86]) }\end{array}$ & $\begin{array}{l}\text { AMPLATZER post-infarction Muscular VSD } \\
\text { Occluder, modified double disc occluder } \\
\text { (Shanghai Shape Memory Alloy Material Co., Ltd) }\end{array}$ \\
\hline Zhu et $\mathrm{al}^{21}$ & 35 & 2013 & $\begin{array}{c}\text { 65, IQR } 57-72 \\
(-)\end{array}$ & $\begin{array}{c}13 / 35 \text { (37) } \\
(5 \text { [IQR 2-7]) }\end{array}$ & $\begin{array}{c}22 / 35 \text { (63) } \\
(23 \text { [IQR 18-36]) }\end{array}$ & $\begin{array}{l}\text { AMPLATZER post-infarction Muscular VSD } \\
\text { Occluder, modified double disc occluder } \\
\text { (Shanghai Shape Memory Alloy Material Co., Ltd) }\end{array}$ \\
\hline Sum & 273 & & & $110 / 237(46)$ & $127 / 237(54)$ & \\
\hline
\end{tabular}

implantations, and number of primary percutaneous VSD procedures are outlined in Table 2.

\section{PATIENT CHARACTERISTICS}

The mean patient age was 70.3 years. In total, $69.4 \%$ of patients were male (145/209). The rate of individuals in CS was $47.9 \%$ $(114 / 238)$ at the time of intervention, and 58.4\% (122/209) had an IABP placed prior to VSD occlusion. Anterior/apical myocardial infarction causing the VSD was present in $56.9 \%$ of patients $(145 / 255)$. Coronary single-vessel, double-vessel and triple-vessel disease was present in $61.9 \%$ (128/207), 24.6\% (51/207), and $13.5 \%(28 / 207)$ of patients, respectively.

\section{DEVICES}

Septal defect occluders used share a common morphology. The majority of studies used one of three Amplatzer ${ }^{\mathrm{TM}}$ (St. Jude Medical, St. Paul, MN, USA) device subtypes - the AMPLATZER $^{\text {TM }}$ Septal Occluder, the AMPLATZER ${ }^{\mathrm{TM}}$ Muscular VSD Occluder and the AMPLATZER ${ }^{\mathrm{TM}}$ P.I. Muscular VSD
Occluder, the latter specifically designed for post-infarction VSD closure (Figure 1). One study summarising the early experiences with post-infarction VSD occlusion reported on the use of the Clamshell device (C.R. Bard, Murray Hill, NJ, USA), the CardioSEAL $^{\circledR}$ (NMT Medical, Boston, MA, USA) device, and the STARFlex ${ }^{\circledR}$ device (NMT Medical) ${ }^{10}$. Only two more reports included devices of a non-Amplatzer occluder (modified double disc occluder [Shanghai Shape Memory Alloy Material Co.,
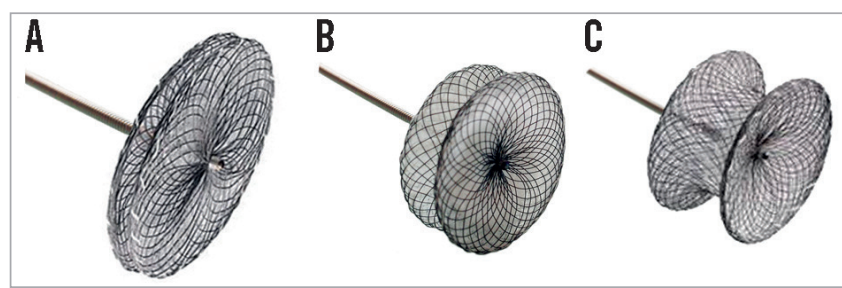

Figure 1. Amplatzer occluders. A) AMPLATZER Septal Occluder. B) AMPLATZER Muscular VSD Occluder. C) AMPLATZER P.I. Muscular VSD Occluder. 
Table 2. Characteristics of studies: outcome.

\begin{tabular}{|c|c|c|c|c|c|}
\hline Study & $\begin{array}{c}\text { 30-day or } \\
\text { in-hospital } \\
\text { mortality; n/N (\%) }\end{array}$ & $\begin{array}{l}\text { 30-day or in-hospital } \\
\text { mortality primary } \\
\text { closure; n/N (\%) }\end{array}$ & $\begin{array}{c}\text { Cardiogenic } \\
\text { shock; n/N (\%) }\end{array}$ & $\begin{array}{c}\text { Successful device } \\
\text { implantation; } \\
n / N(\%)\end{array}$ & $\begin{array}{c}\text { Primary VSD } \\
\text { closure; n/N (\%) }\end{array}$ \\
\hline Assenza et $a^{10}$ & $7 / 30(23)$ & $5 / 30(17)$ & $17 / 30(57)$ & - & $12 / 30(40)$ \\
\hline Ahmed et $\mathrm{al}^{11}$ & $2 / 5(40)$ & $2 / 5(40)$ & $3 / 5(60)$ & $4 / 5(80)$ & $3 / 5(60)$ \\
\hline Bialkowski et al ${ }^{12}$ & $5 / 19(26)$ & $5 / 19(26)$ & - & $17 / 19(90)$ & $14 / 19(74)$ \\
\hline Calvert et al ${ }^{13}$ & $18 / 53$ (34) & - & $26 / 53$ (49) & $47 / 53$ (89) & $43 / 53(81)$ \\
\hline Demkow et $a^{14}$ & $2 / 11(18)$ & $2 / 11(18)$ & - & $10 / 11(91)$ & $10 / 11(91)$ \\
\hline Holzer et al ${ }^{20}$ & $5 / 18(28)$ & - & $10 / 18(56)$ & $16 / 18(89)$ & $8 / 18(44)$ \\
\hline Maltais et $\mathrm{al}^{15}$ & $5 / 12(42)$ & $5 / 12(42)$ & $5 / 12(42)$ & - & $12 / 12(100)$ \\
\hline Marinakis et al ${ }^{16}$ & $6 / 8(75)$ & $6 / 8(75)$ & $4 / 8(50)$ & - & $7 / 8(88)$ \\
\hline Martinez et al ${ }^{17}$ & $1 / 5(20)$ & $1 / 5(20)$ & - & $4 / 5(80)$ & $4 / 5(80)$ \\
\hline Thiele et $\mathrm{al}^{7}$ & $19 / 29(66)$ & $19 / 29(66)$ & $16 / 29(55)$ & $25 / 29(86)$ & $25 / 29(86)$ \\
\hline Trivedi et al ${ }^{18}$ & $3 / 6(50)$ & $2 / 6(40)$ & $4 / 6(75)$ & $6 / 6(100)$ & $5 / 6(83)$ \\
\hline Xu et al ${ }^{19}$ & $8 / 42$ (19) & - & $16 / 42(38)$ & - & $39 / 42$ (93) \\
\hline Zhu et $\mathrm{al}^{21}$ & $5 / 35(14)$ & $5 / 35(14)$ & $13 / 35(37)$ & $32 / 35(91)$ & $32 / 35(91)$ \\
\hline Sum & $86 / 273(32)$ & $52 / 178(29)$ & $114 / 238(48)$ & $161 / 181$ (89) & $214 / 273(78)$ \\
\hline
\end{tabular}

Ltd, Shanghai, China] $)^{21}$. The device size was determined using echocardiography in the majority of cases, with fluoroscopic balloon-based sizing performed in a minority of $\operatorname{cases}^{12,13}$. Figure 2 demonstrates an Amplatzer device implantation for VSD.
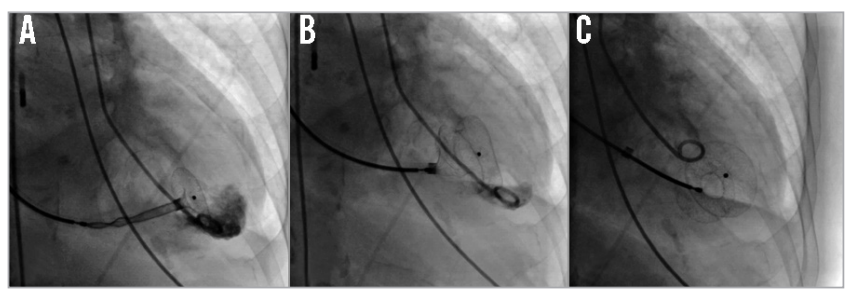

Figure 2. Device implantation. A) Compressed double umbrella device advanced over the guidewire via the VSD into the left ventricle after release of the left ventricular double umbrella. B) Left ventricular disc fully developed, right-sided disc partially opened. C) Left and right ventricular disc fully opened and released from the delivery system.

\section{PATIENT SELECTION}

In the retrospective report by Assenza et al, representing the longest time interval under investigation (1988-2008), 30 patients with VSD were included (12 primary, 18 secondary device closures). The indication for device closure was based on the presence of heart failure and pulmonary overcirculation that did not respond to medical therapy. Eligibility was not based on prospective criteria and a surgical option was denied by consensus in all patients. Multiorgan failure had a very high mortality rate irrespective of the closure attempt ${ }^{10}$.

The first five consecutive cases of interventional VSD closure of the Auckland City Hospital were described in another report. The authors included two cases of prior surgical closure with residual shunt and one acute phase patient treated on day two after AMI. In this patient, device delivery was unsuccessful due to an inability to cross the defect and the patient died shortly afterwards ${ }^{11}$

In the largest series to date, the UK experience is summarised retrospectively ${ }^{13}$. Electronic case records were circulated to centres that reported VSD device closure cases in a national database. No further selection criteria were applied.

Bialkowski et al reported on 19 patients receiving percutaneous VSD device closure, two for closure after surgery and 17 for primary VSD. The authors stratified the outcome according to closure attempt in the acute, subacute and chronic phases of VSD, while no restrictions on eligibility were outlined ${ }^{12}$.

Immediate device therapy was the preferred primary therapy in all patients with VSD in the prospective study by Thiele et al. The authors reported a high rate of CS patients (55\%). Only morphological echocardiographically evaluated exclusion criteria were applied. These included a VSD size of $>35 \mathrm{~mm}$, an apical VSD without a suitable rim and a basal VSD too close to the valvular apparatus. However, these criteria did not lead to any exclusion of patients?

Martinez et al reported the retrospective Mayo Clinic experience of percutaneous VSD occlusion. No further restrictions were applied $^{17}$.

Only VSD patients with a significant left-to-right shunt (Qp:Qs $\geq 1.5$ ) and a defect size as well as location suitable for device therapy were considered in another series comprising nine patients ${ }^{14}$.

Holzer et al evaluated patients for interventional closure on a case-by-case basis and applied no general clinical or haemodynamic exclusion criteria. A defect size exceeding $24 \mathrm{~mm}$ was considered unsuitable. In cases of prior unsuccessful surgical attempts, technically challenging VSD location or in patients with high surgical risk, device closure was preferred to surgery ${ }^{20}$. 
The experience of the Montreal Heart Institute is summarised in another study by Maltais et al. Percutaneous treatment was considered on an individual basis in all patients with a VSD diameter $<15 \mathrm{~mm}$ and in unstable patients with high surgical risk. The authors proposed a new treatment algorithm, rendering patients with a small or medium VSD suitable for percutaneous occlusion, facilitating delayed surgical correction in case of a significant residual VSD ${ }^{15}$. Initial single-centre results of eight patients were reported in another study, with percutaneous closure attempts performed within one week of myocardial infarction and haemodynamic deterioration in all but two patients ${ }^{16}$.

Zhu et al prospectively evaluated the feasibility of concomitant VSD device closure and coronary revascularisation in a 35-patient multicentre registry. A defect size in excess of the maximum available occluder device was considered inappropriate for percutaneous closure $^{21}$. In a relatively large analysis, 42 patients ineligible for cardiac surgery entered a retrospective registry. Patients with congenital muscular VSD were excluded ${ }^{19}$.

Finally, in the analysis of Trivedi et al data, all patients undergoing treatment for VSD following acute myocardial infarction in three French hospitals were analysed. No further inclusion or exclusion criteria were defined ${ }^{18}$.

\section{TIMING}

Great heterogeneity concerning the timing of the interventional approach was observed. In summary, $46.4 \%$ of patients $(110 / 237)$ were treated percutaneously within the first two weeks after VSD detection. A linear relationship exists between the number of acute phase cases (occlusion $<14$ days after AMI) included in the individual studies and a higher mortality $(r=0.72, p=0.01$ ) (Figure 3). Only one study specifically targeted the acute phase of VSD occurrence ${ }^{7}$.

\section{COMPLICATIONS}

A number of complications occurred in this severely compromised patient population. There was a total of 36 procedure-related

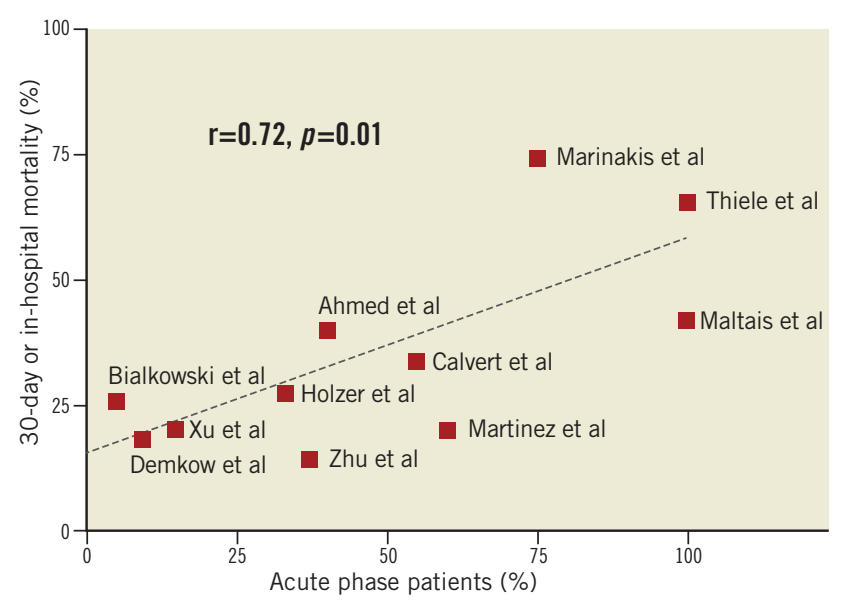

Figure 3. Acute phase device closure and mortality. Correlation analysis between number of acute phase patients included $(<14$ days after AMI) and 30-day/in-hospital mortality. complications. Among those reported were arrhythmias of differing degrees (three transitory $3^{\text {rd }}$ degree atrioventricular blocks) ${ }^{10,12}$ and one $3^{\text {rd }}$ degree atrioventricular block after crossing the VSD with the delivery sheath with consecutive death before implementation of pacing despite cardiopulmonary resuscitation ${ }^{7}$, one electromechanical dissociation with consecutive death ${ }^{10}$, eight reports of ventricular fibrillations/tachycardias ${ }^{11,12,19,21}$, and one report of atrial flutter terminated by cardioversion ${ }^{11}$. Furthermore, there was a report of two bradycardias associated with the implantation of the VSD occluder, which were not further specified ${ }^{20}$.

Appropriate sizing of the VSD occluder remains a matter of debate due to the broad variety of anatomy and tissues found in VSD. As a result, in total seven device embolisations have been reported $^{7,10,13,20}$. One device embolised into the pulmonary artery and led to the death of the patient ${ }^{15}$.

Thiele et al described three cases of left ventricular rupture after closure $^{7}$. There was one case of an iatrogenic right ventricular perforation ${ }^{15}$. One case of left ventricular dysfunction after the procedure was reported ${ }^{20}$. VSD occluder-related haemolysis was reported in one case ${ }^{12}$. Procedure-related blood loss or haematoma necessitating blood transfusion occurred in nine cases ${ }^{11,13,19,20}$. Finally, ventricular rupture related to the manipulation of the VSD positioning was reported in two patients enrolled in the same cohort ${ }^{19}$.

\section{SUCCESSFUL DEVICE IMPLANTATION/MORTALITY}

The overall successful device implantation rate was $89.0 \%$ (range: $80-100 \%)^{7,11-14,17,20,21}$. The total number of deaths amounted to 86 , representing an in-hospital or 30-day mortality rate of $31.5 \%$. The studies by Thiele et al and Marinakis et al reported the highest mortality rates $(66 \% \text { and } 75 \% \text {, respectively })^{7,16}$. A logistic EuroSCORE of $70 \%$ was reported in the study by Marinakis et al, representing a severely compromised status prior to implantation $^{16}$. Both studies had CS rates $>50 \%$, and procedural success was $86 \%$ in the report by Thiele et al ${ }^{7}$. The majority of studies did not provide a detailed description of the causes of death.

\section{PREDICTORS OF ADVERSE OUTCOMES}

Ahmed et al reported a case series of five patients and indicated that a better outcome may be achieved if the procedure is delayed relative to the incident event ${ }^{11}$. Assenza et al used univariate analyses to predict the risk of mortality and identified the presence of CS, the use of the $43 \mathrm{~mm}$ STARFlex device, and increasing pulmonary/ systemic flow ratio (at time of VSD closure) as being related to an increase in the mortality risk. Furthermore, the baseline modified Model for End-Stage Liver Disease (MELD) score, excluding the international normalised ratio (MELD)-XI score at the time of VSD closure, proved to be a strong predictor of increased death. A MELD-XI score of 20 had $100 \%$ sensitivity and $87 \%$ specificity for predicting 30-day mortality ${ }^{10}$. By means of multivariate logistic regression analysis, Maltais et al were able to identify residual VSD, time from AMI to VSD diagnosis and time delay between VSD diagnosis and either surgical or percutaneous VSD closure as statistically significant predictors of 30-day and in-hospital mortality ${ }^{15}$. 
Calvert et al demonstrated increased hazard ratios of death in association with female sex, the presence of CS, the use of inotropes, higher creatinine levels, larger defect size and absence of revascularisation therapy for presenting AMI, and a shunt reduction of less than two thirds ${ }^{13}$. Advanced age was identified as a risk factor for VSD occurrence and reduced survival after VSD occlusion ${ }^{13}$.

\section{Discussion}

The results of this systematic review indicate that interventional closure of VSD is a feasible treatment option in carefully selected high-risk patients with VSD. However, these pooled data clearly indicate that interventional VSD closure after AMI remains a highrisk procedure.

The overall mortality rate of percutaneous VSD closure was below or similar to that of several surgical VSD repair series reporting mortality rates ranging between 36 and $81 \%^{2,22-24}$. However, a direct comparison is not possible owing to the non-randomised design and an inherent selection bias with all case series of either surgical or interventional closure. Nevertheless, percutaneous VSD closure may permit avoidance or delay of surgical repair, while providing potentially life-saving therapy to high-risk patients with VSD. In addition, residual shunts of either a primary surgical or primary percutaneous closure may be treated, avoiding re-operation ${ }^{7,25,26}$.

From the first feasibility attempts at percutaneous device VSD closure in the $1980 \mathrm{~s}^{6}$, a quarter of a century has passed and the procedure has received increasing attention in spite of decreasing VSD occurrence ${ }^{27}$.

\section{FEASIBILITY}

Recent reports have demonstrated that interventional VSD closure can be performed successfully $y^{7,10-17,20,21}$. However, currently there is no general consensus on establishing criteria for appropriate suitability. Based on the reports incorporated in this systematic review, the majority of VSD can be treated interventionally. In addition, various different subgroups within the VSD patient population have been investigated, including secondary VSD closure for residual shunt after surgical VSD closure ${ }^{10-13,17,20}$, concomitant percutaneous coronary intervention ${ }^{21}$, and immediate primary percutaneous closure ${ }^{7}$.

The multicentre, prospective GUSTO-I trial and the SHOCK registry reported mortality rates of $94 \%$ and $96 \%$, respectively, in medically managed VSD patients, representing numbers estimated to be close to the natural history of VSD outcomes ${ }^{1,2}$. The advent of surgical closure increased survival rates dramatically, while a significant survival difference exists between surgical closure in the first days after AMI ( $<7$ days after AMI, 54.1\% operative mortality [in-hospital or within 30 days of the index surgical closure]) versus the time thereafter ( $>7$ days after AMI, 18.4\% operative mortality) ${ }^{22}$. Survival rates of interventional VSD device closure were shown to range from 25 to $86 \%$, primarily depending on the presence of CS and the amount of time from AMI because of the inherent selection bias ${ }^{7,10-17,20,21}$. This observation is in line with the surgical closure approach.
In the GUSTO-I trial, all VSD patients with a Killip class of III or IV died ${ }^{1}$. Thus, prevention and timely reversal of CS are of high prognostic relevance. Even in CS patients, immediate primary closure attempts seem to be superior to the devastating results of medically treated patients ${ }^{7}$. The feasibility of percutaneous VSD occlusion is reflected by a class IIb recommendation in current European guidelines on revascularisation ${ }^{5}$.

\section{PATIENT SELECTION}

The primary objective of VSD therapy either surgically or percutaneously is left-to-right shunt reduction. This can be difficult because of the often meandering and dynamic VSD shape. Defect size can vary greatly and more than one VSD is often present. Failure to reduce the shunt results in worse outcomes ${ }^{13,15}$.

While survival to discharge is associated with favourable longterm outcomes ${ }^{7,13}$, procedural success does not necessarily translate into increased survival rates. This was demonstrated in the study by Thiele et al where the 30-day survival rate was only $35 \%$ despite a high percentage of technically successful device implantations $(86 \%)^{7}$.

There is reason to believe that there may be a selection bias in percutaneous closure in relation to surgical closure. Percutaneous closure may have been carried out earlier after VSD detection but anatomically more complex lesions may have been referred to surgical correction.

The timing of VSD closure should be based on the haemodynamic status of the patient and the severity of the condition. Early closure of post-AMI VSD is advisable before establishment of CS and multiorgan failure. In case of established CS, either surgical or interventional closure is strongly indicated to ameliorate the otherwise grim prognosis. If the patient is rendered unsuitable for surgical closure, a percutaneous device therapy should be considered.

Acute phase patients without CS should undergo an immediate closure attempt as haemodynamic status allows. The role of primary percutaneous versus primary surgical closure remains unclear in this patient population. Percutaneous device closure may have a role as a bridge to surgery in selected patients ${ }^{28}$. If IABP fails ${ }^{5,29}$, active left ventricular assist devices may be useful in selected patients as a bridge to definitive treatment ${ }^{30,31}$.

AMI and consecutive VSD location may also play a crucial role because of the proximity of the valvular apparatus and possible interference with valvular function after device deployment in inferior/ posterior VSD.

\section{TREATMENT ALGORITHM}

A practical treatment algorithm is depicted in Figure 4. Haemodynamic deterioration or a new murmur on auscultation should warrant prompt echocardiographic evaluation. After confirmation of a VSD, immediate closure irrespective of haemodynamic status is indicated. In the absence of randomised trials and guideline recommendations, we recommend that the decision whether to operate or to perform percutaneous device closure should be evaluated by a Heart Team based on the complexity of 


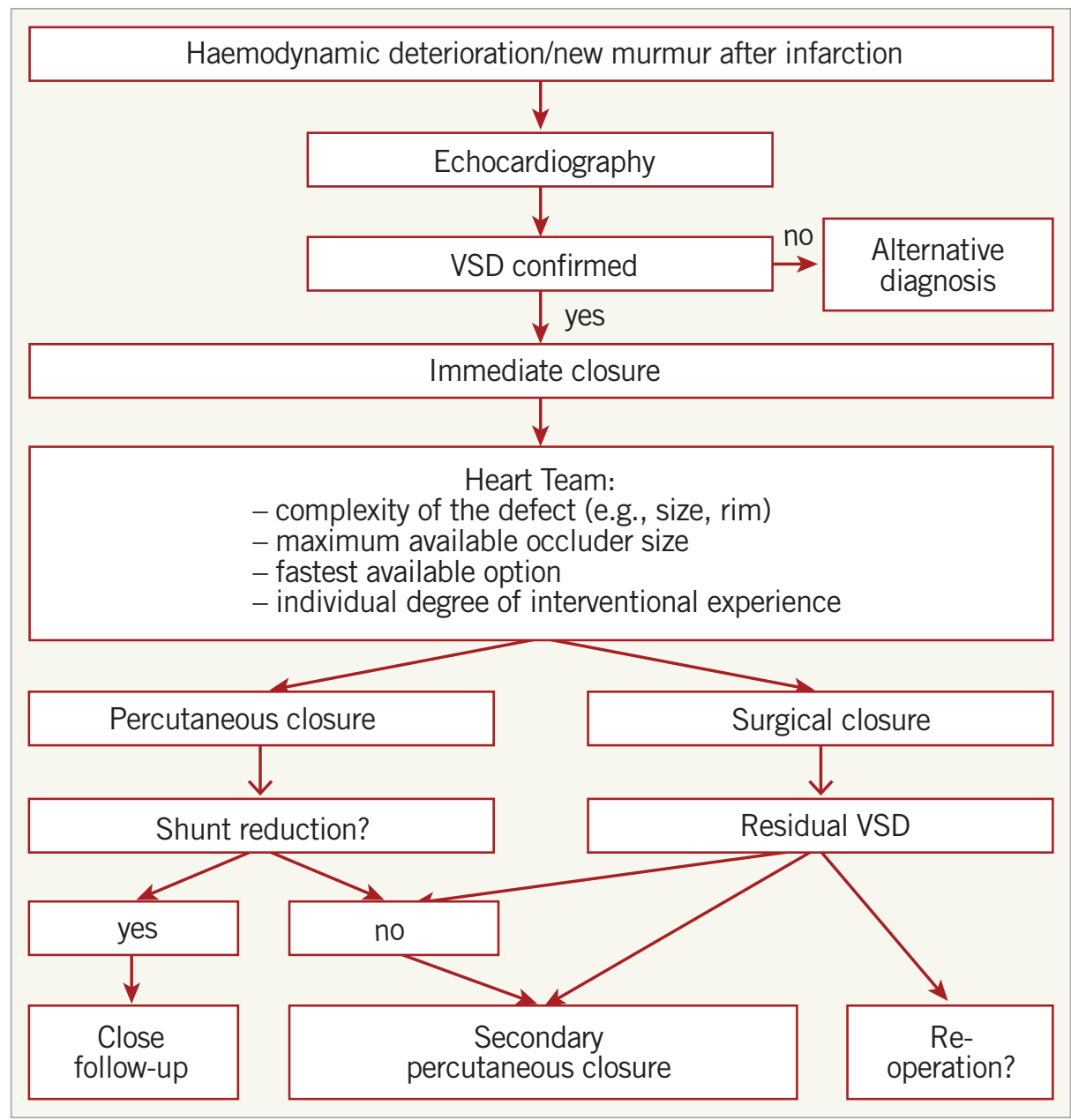

Figure 4. Potential treatment algorithm. Suggested treatment algorithm of ventricular septal defect (VSD) closure.

the defect, the maximum available occluder size, the fastest available option and the individual degree of interventional experience.

If a significant shunt reduction is achieved by either means of occlusion, close follow-up is warranted. If shunt reduction remains insufficient, a secondary percutaneous approach, switch to open heart surgery or in the case of a primary surgical approach a reoperation should be considered.

\section{Study limitations}

Our analysis does not reach the statistical accuracy of a meta-analysis since the underlying data lack a control group and are nonrandomised. However, due to ethical issues and the infrequency of post-infarction VSD, randomised, controlled trials are difficult to perform in this patient population. Therefore, a direct comparison between surgical and interventional, as well as early versus late closure, is not possible owing to the non-randomised design and an inherent selection bias with all case series. Finally, although all VSD closure devices share a common morphology, the performance of different devices might also influence outcome. However, most patients were treated using Amplatzer devices and thus a sub-analysis according to the type of septal defect occluder was not possible.

\section{Conclusion}

In conclusion, percutaneous device closure of post-myocardial infarction VSD may represent a valuable alternative to surgical repair, with the advantage of immediate shunt reduction to prevent haemodynamic deterioration. A high rate of technically successful percutaneous procedures can be achieved. However, especially in CS patients, the mortality rate remains high.

\section{Impact on daily practice}

If left untreated, post-infarction VSD is associated with a devastating prognosis. Percutaneous device closure of postmyocardial infarction VSD is a valuable alternative to surgical repair with high rates of procedural success. Due to the lack of randomised data, the clinical decision regarding the type of treatment (surgical versus interventional approach) needs to be evaluated by a multidisciplinary team based on the complexity of the defect, the maximum available occluder size, the fastest available option and the individual degree of interventional experience. 


\section{Conflict of interest statement}

The authors have no conflicts of interest to declare.

\section{References}

1. Crenshaw BS, Granger CB, Birnbaum Y, Pieper KS, Morris DC, Kleiman NS, Vahanian A, Califf RM, Topol EJ. Risk factors, angiographic patterns, and outcomes in patients with ventricular septal defect complicating acute myocardial infarction. GUSTO-I (Global Utilization of Streptokinase and TPA for Occluded Coronary Arteries) Trial Investigators. Circulation. 2000;101:27-32.

2. Menon V, Webb JG, Hillis LD, Sleeper LA, Abboud R, Dzavik V, Slater JN, Forman R, Monrad ES, Talley JD, Hochman JS. Outcome and profile of ventricular septal rupture with cardiogenic shock after myocardial infarction: a report from the SHOCK Trial Registry. SHould we emergently revascularize Occluded Coronaries in cardiogenic shocK? J Am Coll Cardiol. 2000;36:1110-6.

3. O'Gara PT, Kushner FG, Ascheim DD, Casey DE Jr, Chung MK, de Lemos JA, Ettinger SM, Fang JC, Fesmire FM, Franklin BA, Granger CB, Krumholz HM, Linderbaum JA, Morrow DA, Newby LK, Ornato JP, Ou N, Radford MJ, TamisHolland JE, Tommaso CL, Tracy CM, Woo YJ, Zhao DX, Anderson JL, Jacobs AK, Halperin JL, Albert NM, Brindis RG, Creager MA, DeMets D, Guyton RA, Hochman JS, Kovacs RJ, Kushner FG, Ohman EM, Stevenson WG, Yancy CW; American College of Cardiology Foundation/American Heart Association Task Force on Practice Guidelines. 2013 ACCF/AHA guideline for the management of ST-elevation myocardial infarction: a report of the American College of Cardiology Foundation/American Heart Association Task Force on Practice Guidelines. Circulation. 2013;127:e362-425.

4. Task Force on the management of ST-segment elevation acute myocardial infarction of the European Society of Cardiology (ESC), Steg PG, James SK, Atar D, Badano LP, BlömstromLundqvist C, Borger MA, Di Mario C, Dickstein K, Ducrocq G, Fernandez-Aviles F, Gershlick AH, Giannuzzi P, Halvorsen S, Huber K, Juni P, Kastrati A, Knuuti J, Lenzen MJ, Mahaffey KW, Valgimigli M, van 't Hof A, Widimsky P, Zahger D. ESC Guidelines for the management of acute myocardial infarction in patients presenting with ST-segment elevation. Eur Heart J. 2012;33:2569-619.

5. Windecker S, Kolh P, Alfonso F, Collet JP, Cremer J, Falk V, Filippatos G, Hamm C, Head SJ, Jüni P, Kappetein AP, Kastrati A, Knuuti J, Landmesser U, Laufer G, Neumann FJ, Richter DJ, Schauerte P, Sousa Uva M, Stefanini GG, Taggart DP, Torracca L, Valgimigli M, Wijns W, Witkowski A. 2014 ESC/EACTS guidelines on myocardial revascularization. EuroIntervention. 2015;10: 1024-94.

6. Lock JE, Block PC, McKay RG, Baim DS, Keane JF. Transcatheter closure of ventricular septal defects. Circulation. 1988;78:361-8.

7. Thiele H, Kaulfersch C, Daehnert I, Schoenauer M, Eitel I, Borger M, Schuler G. Immediate primary transcatheter closure of postinfarction ventricular septal defects. Eur Heart J. 2009;30:81-8.
8. Jones BM, Kapadia SR, Smedira NG, Robich M, Tuzcu EM, Menon V, Krishnaswamy A. Ventricular septal rupture complicating acute myocardial infarction: a contemporary review. Eur Heart J. 2014;35:2060-8.

9. Liberati A, Altman DG, Tetzlaff J, Mulrow C, Gøtzsche PC, Ioannidis JP, Clarke M, Devereaux PJ, Kleijnen J, Moher D. The PRISMA statement for reporting systematic reviews and metaanalyses of studies that evaluate health care interventions: explanation and elaboration. J Clin Epidemiol. 2009;62:e1-34.

10. Assenza GE, McElhinney DB, Valente AM, Pearson DD, Volpe M, Martucci G, Landzberg MJ, Lock JE. Transcatheter closure of post-myocardial infarction ventricular septal rupture. Circ Cardiovasc Interv. 2013;6:59-67.

11. Ahmed J, Ruygrok PN, Wilson NJ, Webster MW, Greaves S, Gerber I. Percutaneous closure of post-myocardial infarction ventricular septal defects: a single centre experience. Heart Lung Circ. 2008;17:119-23.

12. Bialkowski J, Szkutnik M, Kusa J, Kalarus Z, Gasior M, Przybylski R, Banaszak P, Zembala M. [Transcatheter closure of postinfarction ventricular septal defects using Amplatzer devices]. Rev Esp Cardiol. 2007;60:548-51.

13. Calvert PA, Cockburn J, Wynne D, Ludman P, Rana BS, Northridge D, Mullen MJ, Malik I, Turner M, Khogali S, Veldtman GR, Been M, Butler R, Thomson J, Byrne J, MacCarthy P, Morrison L, Shapiro LM, Bridgewater B, de Giovanni J, Hildick-Smith D. Percutaneous closure of postinfarction ventricular septal defect: in-hospital outcomes and long-term follow-up of UK experience. Circulation. 2014;129: 2395-402.

14. Demkow M, Ruzyllo W, Kepka C, Chmielak Z, Konka M, Dzielinska Z, Wilczynski J, Juraszynski Z. Primary transcatheter closure of postinfarction ventricular septal defects with the Amplatzer septal occluder- immediate results and up-to 5 years follow-up. EuroIntervention. 2005;1:43-7.

15. Maltais S, Ibrahim R, Basmadjian AJ, Carrier M, Bouchard D, Cartier R, Demers P, Ladouceur M, Pellerin M, Perrault LP. Postinfarction ventricular septal defects: towards a new treatment algorithm? Ann Thorac Surg. 2009;87:687-92.

16. Marinakis A, Vydt T, Dens J, Gewillig M, Van Deyk K, Budts W. Percutaneous transcatheter ventricular septal defect closure in adults with Amplatzer septal occluders. Acta Cardiol. 2007;62:391-5.

17. Martinez MW, Mookadam F, Sun Y, Hagler DJ. Transcatheter closure of ischemic and post-traumatic ventricular septal ruptures. Catheter Cardiovasc Interv. 2007;69:403-7.

18. Trivedi KR, Aldebert P, Riberi A, Mancini J, Levy G, Macia JC, Quilicci J, Habib G, Fraisse A. Sequential management of post-myocardial infarction ventricular septal defects. Arch Cardiovasc Dis. 2015;108:321-30.

19. Xu XD, Liu SX, Liu X, Chen Y, Li L, Qu BM, Wu ZY, Zhang DF, Zhao XX, Qin YW. Percutaneous closure of postinfarct muscular ventricular septal defects: a multicenter study in China. J Cardiol. 2014;64:285-9. 
20. Holzer R, Balzer D, Amin Z, Ruiz CE, Feinstein J, Bass J, Vance M, Cao QL, Hijazi ZM. Transcatheter closure of postinfarction ventricular septal defects using the new Amplatzer muscular VSD occluder: Results of a U.S. Registry. Catheter Cardiovasc Interv. 2004;61:196-201.

21. Zhu XY, Qin YW, Han YL, Zhang DZ, Wang P, Liu YF, Xu YW, Jing QM, Xu K, Gersh BJ, Wang XZ. Long-term efficacy of transcatheter closure of ventricular septal defect in combination with percutaneous coronary intervention in patients with ventricular septal defect complicating acute myocardial infarction: a multicentre study. EuroIntervention. 2013;8:1270-6.

22. Arnaoutakis GJ, Zhao Y, George TJ, Sciortino CM, McCarthy PM, Conte JV. Surgical repair of ventricular septal defect after myocardial infarction: outcomes from the Society of Thoracic Surgeons National Database. Ann Thorac Surg. 2012;94:436-43.

23. Jeppsson A, Liden H, Johnsson P, Hartford M, Rådegran K. Surgical repair of post infarction ventricular septal defects: a national experience. Eur J Cardiothorac Surg. 2005;27:216-21.

24. Mantovani V, Mariscalco G, Leva C, Blanzola C, Sala A. Surgical repair of post-infarction ventricular septal defect: 19 years of experience. Int J Cardiol. 2006;108:202-6.
25. Kaulfersch C, Daehnert I, Schuler G, Thiele H. Transcatheter closure of postinfarction ventricular septal defects. Minerva Cardioangiol. 2007;55:693-701.

26. Webb I, De Giovanni J, Hildick-Smith D. Multiple percutaneous VSD closures post-myocardial infarct. Eur Heart J. 2006;27:552.

27. Moreyra AE, Huang MS, Wilson AC, Deng Y, Cosgrove NM, Kostis JB; MIDAS Study Group (MIDAS 13). Trends in incidence and mortality rates of ventricular septal rupture during acute myocardial infarction. Am J Cardiol. 2010;106:1095-100.

28. Costache VS, Chavanon O, Bouvaist H, Blin D. Early Amplatzer occluder closure of a postinfarct ventricular septal defect as a bridge to surgical procedure. Interact Cardiovasc Thorac Surg. 2007;6:503-4.

29. Thiele H, Ohman EM, Desch S, Eitel I, de Waha S. Management of cardiogenic shock. Eur Heart J. 2015;21:1223-30.

30. Rohn V, Spacek M, Belohlavek J, Tosovsky J. Cardiogenic shock in patient with posterior postinfarction septal rupture--successful treatment with extracorporeal membrane oxygenation (ECMO) as a ventricular assist device. J Card Surg. 2009;24:435-6.

31. Thiele H, Lauer B, Hambrecht R, Boudriot E, Cohen HA, Schuler G. Reversal of cardiogenic shock by percutaneous left-atrialto-femoral arterial bypass assistance. Circulation. 2001;104:2917-22. 